The 16th Economic International Conference New Challenges and Opportunities for the Economy 4.0, May 7-8th, 2020, Suceava, Romania

\title{
A Proposal for Hybrid Agile Approach during Procurement Process of Smart City Solutions
}

\author{
Procopie-Florin GUŞUL, Alina-Ramona BUTNARIU \\ https://doi.org/10.18662/lumproc/ncoe4.0.2020/03
}

How to cite: Guşul, P.-F., \& Butnariu, A.-R. (2020). A Proposal for Hybrid Agile Approach during Procurement Process of Smart City Solutions. In C. Nastase (vol. ed.), Lumen Proceedings: Vol. 13. 16th Economic International Conference NCOE 4.02020 (pp. 22-33). Iasi, Romania: LUMEN Publishing House.

https://doi.org/10.18662/lumproc/ncoe4.0.2020/03 


\title{
A Proposal for Hybrid Agile Approach during Procurement Process of Smart City Solutions
}

\author{
Procopie-Florin GUŞUL ${ }^{*}$, Alina-Ramona BUTNARIU2
}

\begin{abstract}
Smart city is a concept widely used and sometimes the idea seems somehow utopian since it involves notions from a multitude of scientific fields. Most researchers, representatives of companies and government agencies, together with city dwellers agree that the main elements of the smart city are ICT, their successful application and smart human resources. However, it seems that local governments do not pay much attention to educating citizens or raising society's awareness of smart solutions when trying to develop smart cities. Rather, we believe that the major interest in introducing smart city solutions has been an economic one, which would support increasing revenues to local budgets or increasing sales revenues for companies that develop smart solutions. We therefore believe that the demands and expectations of citizens must be listened to (more), frequent result-oriented discussions with smart solutions providers need to take place and that local authorities must establish a clear action plan for all stakeholders to communicate in order to create a smart city that works with success. Therefore, among the characteristics of agile methodologies usually implemented in software development we identified in the current study some concepts that might be applicable to the process of public procurement of smart city solutions. We thus propose a new bybrid agile approach and discuss its advantages with regards to smart city projects. Conclusions of the study indicate that the proposed approach requires changes in public management and, even more important, in our thinking. Customers, typically in the form of municipality or governmental organizations, need to become pro-active and much more engaged in smart city projects. As a result, it is demonstrated that smart governance plays an essential role in the success of the urban projects implemented with such solutions.
\end{abstract}

Keywords: smart city; agile; scrum; public procurement process.

\footnotetext{
1 "Ştefan cel Mare" University of Suceava, Romania, contact@,floringusul.ro.

2 "Ştefan cel Mare" University of Suceava, Romania, alinaramonabutnariu@gmail.com. 


\section{Introduction}

Globalization is continuing to have a major impact on societal progress, on economic and social development and we cannot but observe that it has magnified competition among players of nowadays market. Globalization seems increasingly important mainly because the world is getting more and more unstable and prone to changes that affect many aspects and scientific fields. Another characteristic of today's economic market is that clients are requiring products and services that are customized and made-to-order, personalized after each client's requirements. There is a focus on tailored products, and this might turn out to be such a challenge for organizations to offer since clients' demands go even further to ask for smaller quantities and even single products. In the last several years, organizations have striven to adjust to these market changes and some even adopted lean programs meant to reduce costs. Current paper claims that such an adoption of new and complex methodologies is not enough to maintain and develop competitiveness and satisfaction of clients' interests and is merely a first step into this direction. Moreover, when trying to please the customers' unique needs, an organization is required to take a step forward and integrate concepts such as agility, high-quality and speed of delivery, alongside with an agile mindset that would allow increase in competitive advantage in such turbulent times [1].

Agile methodologies have proven to improve customer value, boost organizational morale, and grant improvement in the quality of products. Still, debates between specialists and practitioners on the adoption of agile have oftentimes disregarded the difficulties associated with the essential organizational change that is needed for the transition to be a successful one. Also, when we consider complex products such as smart city solutions for cities seeking customized development according to their specific needs, there is more to implementing them. Thus, besides technical aspects, a social and organizational approach must be taken into consideration by both developers and organizations willing to use such solutions.

Project management models and product development methodologies have been developing these last few decades around the Agile concepts, especially in combination with the perception of market uncertainty, complexity and ambiguity and the need for adaptability and change [2]. These so-called obstacles are transformed into challenges for organizations and they developed into a wide variety of methods and tools initially implemented in the software development industry, along with 
principles and values postulated by "Manifesto for Agile Software Development" [3]. Characterized by continuous and iterative delivery of a working product or service, Agile methodologies such as Scrum, Kanban or $\mathrm{XP}$ have become standard status quo in the software industry, with fairly success rates in other fields such as banking or automotive. More recently, all kinds of private and even public organizations have turn to agile since the concept is no longer seen as a clearly defined set of tools or methods, but rather as an indicator of team performance [4].

With smart city concept gaining so much popularity amongst cities and smaller towns all over the world, both municipalities and smart city solutions developers are confronted with the challenge of both responding to citizens' needs for an increased quality of life, as well as being efficient with the resources they employ when implementing smart city projects. We consider this to be an interdisciplinary field that demands a high level of cooperation and willingness to integrate common solutions among specialists from different areas that cover economy, mobility, environment, people, living and last, but not least governance. Projects implementing smart city solutions bring thus along a wide variety of new challenges that would benefit all stakeholders: private business, public organizations and citizens. With such an intricate web of multi-level cooperation, methodologies used so far seem to be obsolete and traditional tools are a prerequisite for failure. In turn, we propose that agile methodologies may be, at least in part, applied to the procurement process of smart city solutions to enhance flexibility and ensure delivery of smart solutions customized to the citizens' needs and interests.

\section{Theoretical Background on Agile Project Management}

Agile project management is a specific methodology that has proven its success in several fields, such as software development, manufacturing and so on. The concept of being agile demands a vital behavioral change which influences the thinking processes and acting behaviors of team members in the organization [5]. In a traditional approach, project managers use in their current professional activities structured and planned management, trying to avoid change of plans or even predicting it with specific measures, whereas Agile main focus is to adapt and act towards imminent changes, to focus on innovation, adaptability, people and improved process adjustment, quality and results. For all these reasons and more, we state that agile project management is not suited to any work climate. Therefore, this approach must be adopted only if the company 
integrates agile as an intrinsic principle in its own culture and strategy and variables such as organization, workforce and type of leadership aspects to be considered as well [6].

The concept of agile software development is most usually traced back in 2001, when there took place the release of the Agile Software Manifesto (http://agilemanifesto.org/), which has been founded on 12 principles meant to serve essentially as guidelines for agile software development. According to Dingsøyr, et al., "At its core, agility entails ability to rapidly and flexibly create and respond to change in the business and technical domains." In other words, agility refers to that ability of companies to be smart and quickly adjust to the changing needs, interests and demands, or what Cockburn [7] used to describe as a methodology that promotes flexibility, maneuverability and speed of action.

In their article, Dingsøyr et al. describes a variety of key definitions of agility. Although these definitions deliver some variations on the concept of agility, they also mention common ideas, such as efficiency, leanness, cost effectiveness, speed, simplicity, quality or flexibility.

Despite the fact that a wide range of experts and academia promote the positive and beneficial aspects of adopting agile methodologies, Fridman (2016) in [8] identifies five crucial disadvantages of agile methods, as follows: 1) Less predictability as a reaction to the impossibility to quantify the level of full effort required for an action/task/activity; 2) A need for more time commitment as a result to the close communication processes demanded in agile teams; 3) More requirements on developers and clients; 4) Fewer documentation as a result to the nature of development; 5) Possibility for projects to change their track as a result to constantly changing the redefined needs.

The above-mentioned overview provides the general context in which agile methodologies developed in the private sector. This paper focuses on agile methods in public organizations and the intensity to which these concepts translate - and in what ways - to the public sector. The results of such observations would clearly indicate to the faulty nature of agile methodologies applied in the public nature. Still, some principles seem to be universally appropriate and some success might be registered with a hybrid agile approach.

Some common traits of hybrid methods include, according to [9], a combination of different approaches, practices and principles, adjustments that fit into the organizational culture and governance, operations, and processes, a sensible balance between anticipation and reaction, that is between predictability and adaptability, a combination between several distinct roles and responsibilities according to the project overall context, 
equilibrium between process discipline (bureaucracy, rules) and team's selforganization potential.

The deficiencies of Agile approaches are that customers would like their contracted results in a fixed period and budget. Whereas, in the case of Agile project management, there is no possibility of expressing the exact cost in advance, since it depends on the needs of the customer expressed during the whole duration of the project through debates or discussions held between developer and customer. This alone is considered to be a major problem when handling public contracts, because every citizen is entitled by the law and wants to know exactly how much each and every contract execution will cost. Another shortcoming is that a weak customer involvement directly affects product quality. This means that customers must participate directly in the entire development process and closely cooperate with the developers on the implemented solutions or projects. Next short coming of Agile methods consists of the fact that they have been initially designed for small projects, but lately even larger projects seem to have success and prove their efficiency when agile is implemented [10].

Scrum, an application of Agile methodologies in practice, defines a flexible strategy for product development, in which the development team works as an integrative entity to achieve a common goal. An essential aspect of Scrum is that customers change their minds or continuously develop ideas about what they want and need (usually called "set of requirements"), and that unpredicted tasks will not be solved through simple traditional planning processes before or during the project. Scrum uses an empirical approach that stipulates that the problem cannot be fully defined or understood from the beginning, and thus needs that the team develops its ability to deliver working results quickly and continuously respond to new requirements from the client [11].

Throughout the Scrum process we may identify 3 essential team roles, as follows:

1) A development team is responsible for the delivery of a product developed through a series of increments at the end of several sprints. The team is typically composed of individuals who are performing their current work in phases such as analysis, design, development, test, technical communication, document, etc. [12].

2) A Product Owner represents all stakeholders and embodies the interests of the customer. He/she is responsible will have to ensure that the team bring value to the business. The Product Owner understands the customer requirements and expectations and is responsible to clearly state them to the members of the development team, evaluating at the same time specific working tasks and priorities, by adding them to the product backlog. 
We might view the Product Owner as the business representative of the development who will never interact with the team members during the development process, except for the scheduled meetings, i.e. sprint meetings.

3) The Scrum Master is the key responsible for the removal of barriers from the working route of the team on its way to achieve the goal. The Scrum Master is anything but a traditional team leader or project manager and is the one who acts as a middle person between the team and any negative obstacle. The Scrum Master ensures that the whole Scrum process is implemented the way it was planned, and team members comply with all the processes. He/she has a procedural role to which all team members agree to adhere. Another important artefact in Scrum are meetings which are organized regularly and during which the team members are encouraged to further improvements [13].

A sprint (or an iteration) is the basic unit in Scrum development. The sprint represents time boxed working effort which is restricted from start to a specific period. Each sprint begins with a sprint planning event that focuses on defining a sprint backlog, identifying the work to be achieved for the sprint, and make an estimate for the sprint goal. Each sprint will end with a sprint review and a sprint retrospective. There might also be daily Scrums during a sprint. The overview of the entire Scrum methodology is shown in Figure 1.

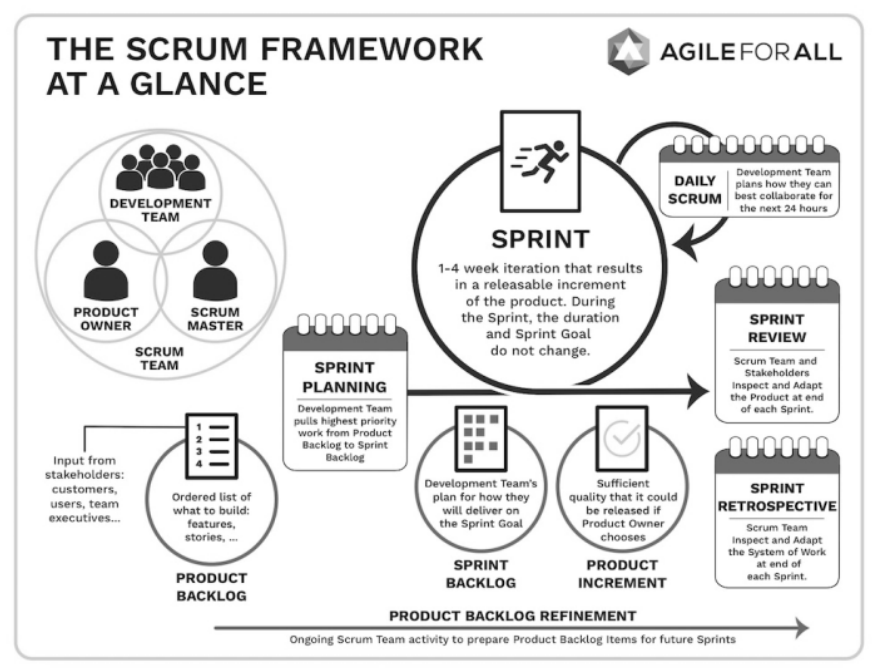

Figure 1. Scrum process framework. 
Gabriela LEUCIUC \& ... | Lumen Proceedings 13 | NCOE4.0 2020

\section{Smart city solutions development, a multidimensional approach}

Urban development and improved quality of urban life are now increasingly dependent on technology. Smart cities are increasingly using information and communication technologies (ICT). Typical smart solutions include various aspects of an urban ecosystem, such as smart infrastructure, smart operation, smart services, smart industry, smart education, smart security systems or ensembles. The concept of a smart city integrates the physical, institutional and digital dimensions of an agglomeration. This approach introduces issues such as interconnection, feedback, selforganization and adaptation to provide an understanding of an almostorganic growth, operation, and evolution of cities. Cities are now turning from digital cities to smart cities, which are more technology-oriented than ever through smart city approach concepts. A city becomes "smart" when it is properly instrumented, interconnected, adaptive, autonomous, always willing to discover or learn, self-repairing and robust. Part of its infrastructure and facilities are digitally connected and optimized using ICT to provide services to their citizens and other stakeholders.

Smart city is a current and very fashionable concept that seems to be becoming more and more important for different stakeholder groups, such as businesses, governments and the general public or civil society. There are many descriptions and different definitions of the concept of smart city. However, there is no universal consensus on its significance and can therefore be perceived as an ambiguous concept. However, for reasons of clarity and despite its indefiniteness in all the meanings it supports, in this paper we align with the definition of the smart city given by Caragliu, Bo and Nijkamp, 2011 [15] who stated that smart city requires investing in human and social capital and traditional (transport) and modern (ICT) infrastructure promotes sustainable economic growth and a high quality of life, with intelligent management of natural resources, through participatory governance.

Specialists in various fields have suggested definitions for the smart city, such as:

- A "smart" city uses information and communication technology (ICT) to improve its viability, strength and sustainability [16].

- A smart city might be seen as a determined geographical space, able to manage resources (natural, human, equipment, buildings and infrastructure), as well as waste generated by lifestyle; it should be sustainable and friendly to the environment. 
To shed more light on this still unclearly defined concept, we conform to [17] who, in a report for the European Union, conceptualized the smart city in six areas: government, economy, life, environment, people, and mobility.

Taking Giffinger definition into consideration, smart city topic is a multi- and interdisciplinary discipline that demands a high level of cooperation between specialists from a wide variety of different scientific fields. The notion of the smart city should not be seen exclusively as a technical discipline, but it is necessary to also include economic, social and legal approaches. Systems integrated in smart city should closely cooperate sharing data, information and other resources so as to achieve estimated results and objectives. A clear-cut distinction between fields of interests will not be of any success when implementing smart city solutions since this segregated approach will not ensure integrative implementation through cooperation and sharing of resources.

The main challenges facing cities in the field of smart governance are the urgent need to change the governance model. Governing in a traditional city, based on top-down policies, has proven to be ineffective in achieving satisfaction among citizens and, moreover, cannot reach certain parts of society that are mostly informal. Governance models will face the challenge of becoming more flexible, allowing combinations of top-down policies with bottom-up initiatives and also informality.

To be more specific, a mobility smart solution might come up into discussion. We cannot look at the public transport system in terms of merely the amount of CO2 emissions. We must look at it in terms of other disciplines as well. When investigating more advanced mobility smart tools that would enhance citizens experience when using the public transport system, we must take into consideration besides environmental data, legal and social aspects. It is not possible simply to gather data through sensors that are being placed on public buildings or transport. Information gathered in this manner is clearly more efficient to be used and transformed into open data, but it is not as easy as one might think. Respecting the legal provisions and having into consideration security of such data must be taken also into account. An interdisciplinary team of architects, engineers, lawyers and even public managers should implement and oversee this smart mobility project.

Smart solutions are being developed frequently by private companies for public municipalities and in this regard there are strict methodologies for procurement process and management of public contracts co-financed by the European Union. Each member state also has national laws and norms on how to implement the public procurement process. In Romania, the public procurement law no. 98/2016 describes in detail the manner in which 
a contract is awarded, what a contractor has to comply, what are the specific criteria for winning the contract or implement the contract after winning it. In short, the current state of the procurement process in Romania is graphically represented in Figure 2.

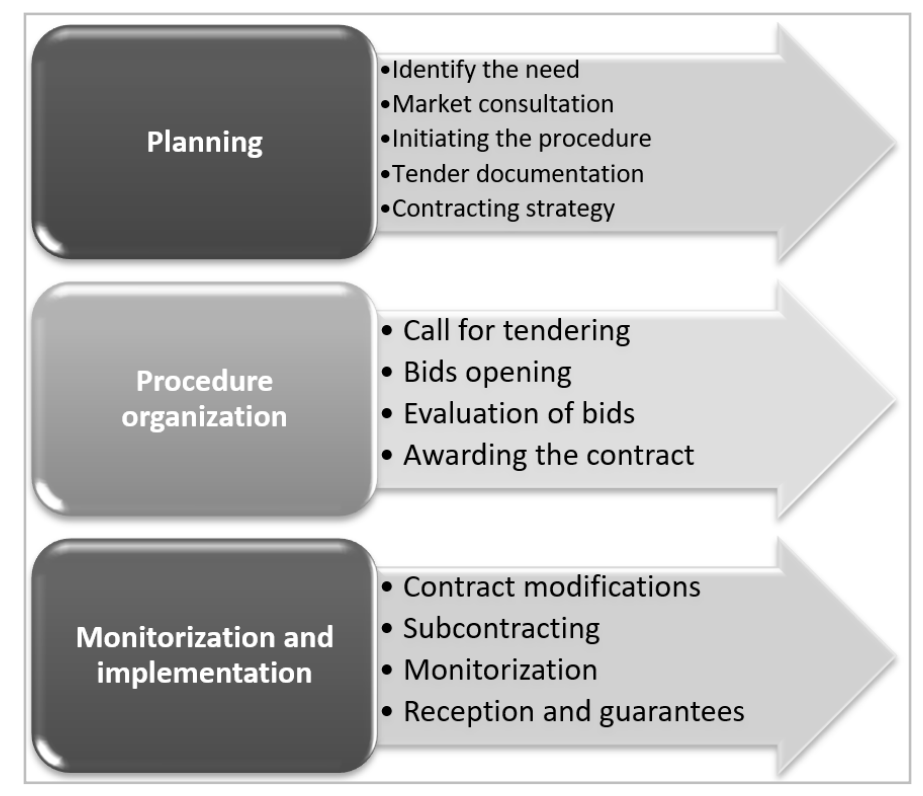

Figure 2. Public procurement process in Romania according to Law 98/2016. Source: authors' contribution

The big disadvantages of the current procurement process are that cooperation among different fields is not encouraged by the public system. In Romania, with few exceptions, there is a practice that a general contractor wins a whole contract. The most frequent criterion for award is the lowest price and this leads to the efforts of most companies to win the contract with the price lower than the cost. This turns out to be very inefficient and often leads to situations in which companies are looking for the cheapest and not the most qualitative solutions. Moreover, communication during the development process is frequently not coordinated, which, in turn, leads to a poor implementation of the contract, inadequate results and an unsatisfied client. For these reasons we propose a hybrid agile new approach in which management of the entire procurement process and the implementation of the contract is made using agile principles. 
Gabriela LEUCIUC \& ... | Lumen Proceedings 13 | NCOE4.0 2020

\section{A proposal for hybrid agile approach in smart cities procurement process}

We have presented so far a short overview of both Agile methodologies needed for any system development process, as well as some characteristics of smart city challenges in the framework of the Romanian public procurement process. Still, we consider that the currently used methodologies are inappropriate for the challenges that are linked to smart cities. We therefore propose in this section a new approach based on some agile principles.

When dealing with the smart cities procurement process, a new hybrid methodology combining the agile principles with the traditional management is needed. It becomes clearer, that tackling the challenges of smart cities demands an essential transformation in our thinking and problems need creative and fast-paced solutions in order for beneficiaries to enjoy the best results. We propose to construct this innovative hybrid approach based on the well renowned 12 principles of agile with certain adjustments, integrative part of our proposal. For the beginning, various roles which are Scrum characteristic should be reinvented and replicated differently. These roles emanate from agile methodology, but their interpretation might differ.

The most crucial role belongs to the Product Owner (PO). S/he is the one that understands the customer needs and expectations, technical terms and is able to take some decisions on regularly during the process. We regard this role to be difficult and technical to award it to the customer since the latter rarely possesses the required technical knowledge. At the same time, the Product Owner of the solution provider will never have the decision making power and precious time and energy would be lost with every decision having to be validated by the customer. Consequently, we propose a model of two Product Owners in this hybrid agile approach: one from the customer (PO-C) and the second from the solution provider (PO$\mathrm{P})$. They would have to work closely together and cooperate each step of the process with each other. This will turn out to be a difference between the agile and the hybrid-agile approach. We view as highly important that both Product Owners are integrative part of the entire process and have a vital role in communication process between both parties involved. As a result of their cooperation, their negotiations will always translate into requirements easy and clearly followed by the whole team.

Other roles, such as the development team or the Scrum Master are performing in a similar way to the standard agile methods. 
The basic principles and adjustments as an alternative to the standard agile methodologies are provided below:

1) The customer (municipality) must be fully involved in all project steps in which smart solutions are going to be developed. By this we do not mean preparing the tendering and selection of the solution provider simply by following the law, but also by providing continuous feedback to the developers and taking fast-paced and relevant decisions during the implementation of the contract. Both Product Owners should be fully responsible to collect the requirements and to present them to the team during regularly held meetings. This is in our vision an ongoing activity, not an activity performed once at the beginning. When questions or challenges are presented, the Product Owner on the customer side (PO-C) must be ready to take definite decisions.

2) The requirements (regularly in the form of common tender documentation) play a vital role in the development process. Since the public organization is mandated by the law to manage the project transparently, the contract objective must be known through requirements from the very beginning of the procurement process. However, in some procurement processes design and execution might be procured together and this hybrid approach minimizes the major problem with requirements in the sense that customer expectations might be negotiated according to some of partial working results. To be more clear, in a procedure that implies both design and execution, a partial working result might be design documentation that may be adjusted along the implementation of the contract so as the solution execution gets the best results which are not always the ones that are initially estimated. The key role of both PO is vital in this kind of procedures since their knowledge and decision-making abilities will ensure the success of a contract. With such an approach, we are able to prepare a project plan and implement the project while at the same time minimizing some of the discrepancies in expectations between the customer and the solution provider.

3) The whole contract could be divided into short cycles, i.e. the socalled Scrum sprints (with a recommended duration of one to four weeks) and this might be an excellent solution to any changes. The Product Owner collects requirements and is introduces them into the Product Backlog, while they are further processed by the members of the development team. At the beginning of each sprint, a sprint planning meeting could take place. The biggest advantage of this sprint approach is that customers could monitor the progress on a regular basis and make adjustments if necessary, at the end of each sprint. The scope of these sprints is, similar to traditional Scrum 
methodology, to provide a detailed overview as well as to plan next steps of action during a following sprint cycle.

4) Change and not boldness to confront it is an important agile principle and also difficult to implement in public organizations. To change specifications and requirements should not be expensive or resource consuming in whatever phase of the project these might occur. This aspect is the one that requires a full and absolute change in the mindset of all parties involved, that is the procurers, the developers and other stakeholders as well. During planning phase and even early implementation of the contract, it is not possible to know exactly the customer needs and predict what might occur during the execution phase (for example, newer technologies). This principle states that both the customer and the developer should not fear of new requirements and specification during the implementation if this would help to simplify and minimize the costs of the entire process. However, since the PO-C is closely involved in the process, $\mathrm{s} /$ he must be able and ready to justify any changes to citizens since there is a public contract and it must be traceable and properly monitored.

5) Tight daily collaboration between public organization representatives and developers is another principle to be applied, besides frequent communication between both Products Owners. We consider that face-to-face communication is the best form in which messages are properly transmitted and no blockages threaten to appear. Indeed, particular attention should be paid that this type of informal communication is nor overly abused and poorly documented.

6) The measure of success in any procurement process is the fulfilment of the contract. Changes to the contract, in the form of amendments or addendums are not an indication of the contract failure, but of the fact that requirements were improved organically, through negotiations between customer and developer. With that in mind, changes should contribute to an improved performance of the smart solution system.

7) Sustainable development is a constant desideratum that must not be overlooked even when applying such innovative methodologies such as agile or hybrid agile. The implementation pace should be sustainable throughout the project, but quality of the results is much more important than speed of task performing. In other words, team members should keep their focus on the relevant results and adjust methodology when needed, not the other way around.

8) Keeping things simple might be the key for maximizing the amount and quality of performed work, as well as not executed tasks. This fundamental principle of the agile stipulates that only what is necessary should be done. This means that the Product Owner and the members of 
the development team are in charge of always and properly analyzing whether the task should be performed and whether it contributes to the project performance. Moreover, there is a constant need to assess in which manner a certain task will help other savings of further resources. This turns out to be an extremely complex action and the experience of the team is of utmost importance for applying this principle.

If we analyze the above-mentioned principles, we discover that the application of the hybrid-agile approach to smart cities procurement process has the capacity to solve major disadvantages of the public procurement system which is overly governed by bureaucracy, formality, time-consuming and inefficient in dealing with changes and other immediate challenges.

One of the shortcomings of an agile approach is the incapacity to determine and comply to a definite final price and delivery date beforehand. By implementing a hybrid agile approach, we consider that the team will no longer focus entirely on documenting requirements. Furthermore, the progress is monitored on a regular basis through constant information, which is, in the end, the success key of a project. In other words, once the customer is timely informed about any new challenges through regular sprints, the decision-making process is half-way stimulated. One major advantage of applying such a hybrid-agile approach is in gaining partners' trust by cooperating with relevant stakeholders, i.e. the cooperation between the developer, the customer and other specialists throughout the project implementation. The best possible results could be achieved in the shortest time and with a minimum use of resources, by sharing information among all parties involved in the project. In this manner could a municipality meet the objectives of smart cities that require collaboration from experts in different fields. Having determined the role of both Product Owners with strong focus on the face-to-face communication, such model of cooperation will lead to maximizing results with real benefits for the citizens.

There is no doubt that supplementary project costs might occur during the project lifetime, but a strong communication process will eliminate the risk of misunderstandings between the customer and the provider. The general scope of the project that implies procurement of design and execution of smart solutions, along with directions are set from the beginning of the procurement process through the requirements. Nonetheless, Product Owners on behalf of both customer and developer is an essential element that has a vital role in a functional hybrid-agile approach implemented in a public organization. 


\section{Conclusions}

The current paper discusses the necessity to use innovative methodologies for projects in the field of smart cities. Some methods and principles of Agile, as well as the specifics of smart city interdisciplinarity are introduced and discussed in more details. However, authors consider that exclusively Agile or traditional methodologies are not fully suitable for the challenges that imply implementation of smart city projects. The main focal points are the emphasis on the cooperation and the communication between different fields, constant feedback and a pro-active approach on behalf of the customer, similarly to creating highly engaged interdisciplinary teams. With the aim of overcoming current bureaucratic and resource-consuming challenges of the procurement process in Romania, a new hybrid-agile approach was proposed in this paper.

This hybrid agile model that we propose is based on the 12 elementary principles of the Agile development and is essentially using the best fitted characteristics of Scrum methodology. Some basic alterations and principles are discussed and the main hypothesis is that public organizations need a major shift in their thinking processes in application of this new methodology. Strong accent should be put on developing smart projects and municipalities or governmental organizations have to take into consideration recruiting adequate personnel to face challenges of nowadays, such as immediate changes, new technologies and public pressure.

The agile principles require a pro-active attitude and much more involvement of contracting authorities in the smart city projects. It is not enough to prepare tender documentation and expect that final results are achieved and similar to what was expected. The entire development system must be built incrementally and the customer is required to be constantly involved in all stages throughout the entire project duration to ensure smart solutions that are adequate to local development.

As Buchem, Attwell and Eds, 2013 [18] stated, "a city cannot be smart without smart citizens". We also claim that a city cannot be smart without smart government. As a consequence, this paper provides relevant information about the manner in which a smart municipality could improve the development process of smart city solutions with support of novel technologies such as agile approach. 


\section{References}

[1] Balaji M, Velmurugan V, Subashree C. "TADS : An assessment methodology for agile supply chains," Revista Mexicana de Trastornos Alimentarios. Universidad Nacional Autónoma de México, Centro de Ciencias Aplicadas y Desarrollo Tecnológico. 2015; 13(5): 504-509. doi: 10.1016/j.jart.2015.10.002.

[2] Rebentisch E. et al. "Defining Scaling Strategies for the Improvement of Agility Performance in Product Development Projects," Procedia CIRP. Elsevier B.V., 70; 2018: 29-34. doi: 10.1016/j.procir.2018.01.006.

[3] Manifesto for Agile Software Development. Available from: http://agilemanifesto.org/

[4] Carlos E. et al. "Science Direct The agility construct on project management theory,"2016; 34: 660-674.

[5] Sherehiy B, Karwowski W, Layer KL. "A review of enterprise agility: Concepts , frameworks , and attributes," 2007; 37: 445-460. doi: 10.1016/j.ergon.2007.01.007.

[6] Dingsoyra T et al. "A decade of agile methodologies: Towards explaining agile software development," The Journal of Systems and Software, 2012; 85: 1213-1221. doi: 10.1016/j.jss.2012.02.033.

[7] Cockburn A. Agile software development: The comparative game. Boston, MA: Addison-Wesley; 2006.

[8] Mergel I, Gong Y, Bertot J. "Agile government: Systematic literature review and future research," Government Information Quarterly, 2018. doi: 10.1016/j.giq.2018.04.003.

[9] Conforto EC et al. "Agile project management and stage-gate model A hybrid framework for technology-based companies," Journal of Engineering and Technology Management Elsevier B.V.; 2016. doi: 10.1016/j.jengtecman.2016.02.003.

[10] Schwaber K. "The Scrum Guide TM," (November); 2017.

[11] Highsmith JR. Agile project management: creating innovative products. Pearson Education; 2009.

[12] Rigby DK, Sutherland J, \& Takeuchi H. Embracing agile. Harvard Business Review; 2016; 94(5), 40-50. doi: https://hbr.org/2016/05/embracing-agile.

[13] Rubin KS. Essential Scrum. A Practical Guide to the Most Popular Agile Process; 2013.

[14] Agile For All. Intro To Agile. Available from: http://www.agileforall.com/intro-to-agile/

[15] Caragliu A, Del Bo C, and Nijkamp P. "Smart Cities in Europe"; 3rd Central European Conference in Regional Science - CERS, 2009. doi: 
Gabriela LEUCIUC \& ... | Lumen Proceedings 13 | NCOE4.0 2020

10.1080/10630732.2011.601117.

[16] Achmad, KA et al. "Smart City Readiness based on Smart City Council's Readiness Framework Smart City Readiness b ased on Smart City Council' s Readiness Framework," (April 2020); 2017. doi: 10.11591/ijece.v8i1.pp. 271-279.

[17] Giffinger R, Fertner C, Kramar H, Kalasek R, Pichler-Milanovic N, Meijers E. "Smart cities - Ranking of European medium-sized cities,"; 2007.

[18] Buchem I, Attwell G, Eds GT. Learning and Diversity in the Cities of the Future; 2013. 